\title{
Robotic transduodenal ampullectomy: Case report and review of the literature
}

\author{
Yun Le Linn ${ }^{1}$, Zhongkai Wang ${ }^{1}$, and Brian K. P. Goh ${ }^{1,2}$ \\ ${ }^{1}$ Department of Hepatopancreatobiliary and Transplant Surgery, Singapore General Hospital, \\ ${ }^{2}$ Duke-National University of Singapore Medical School, Singapore
}

\begin{abstract}
Ampullary neoplasms are relatively uncommon lesions with a risk of progression to malignancy. Depending on its nature, size and location, it may be best treated with endoscopic papillotomy, pancreaticoduodenectomy or transduodenal ampullectomy. Transduodenal ampullectomy offers a higher chance of complete resection compared to endoscopic papillotomy, and carries lower morbidity than a pancreaticoduodenectomy, making it the ideal choice for localised ampullary tumour not involving the ducts but not amenable to complete endoscopic resection. While traditionally performed via open surgery, it has been attempted via laparoscopic approach and more recently robotic approach. We present a case of a 63-year-old man who underwent a robotic transduodenal ampullectomy for ampullary adenoma with high grade dysplasia, and review the literature surrounding robotic transduodenal ampullectomy. (Ann Hepatobiliary Pancreat Surg 2021;25:150-154)
\end{abstract}

Key Words: Ampullary neoplasm; Transduodenal ampullectomy; Robotic surgery; Minimally invasive surgery

\section{INTRODUCTION}

Tumours of the ampulla of Vater or ampullary neoplasms may be benign or malignant. ${ }^{1}$ These are relatively uncommon with incidence rates of less than $0.5 \%$ per 100,000 , and account for less than $1 \%$ of gastrointestinal cancers. As malignant tumours may develop from adenomas via the adenoma-carcinoma progression, benign ampullary lesions should be completely resected in most patients. ${ }^{2}$

The procedure of choice for resection of ampullary tumours have evolved over the years, and includes endoscopic papillectomy (EP), pancreaticoduodenectomy (PD) and transduodenal ampullectomy (TDA). ${ }^{3}$ While EP is a minimally invasive procedure which is increasingly adopted for benign tumours, it is only applicable for tumours not involving the pancreatic ducts or common bile ducts. On the other hand, PD represent a much more invasive treatment choice for radical resection of malignant tumours that has significant associated postoperative mortality and morbidity. TDA has been used as an alternative treatment in patients with tumour not amenable for EP but are poor candidates for PD.

TDA has traditionally been performed via an open approach since its inception. ${ }^{4}$ As early as 2003 , this procedure was reported to have been performed via a laparoscopic approach. ${ }^{5}$ However, adoption of TDA especially via conventional laparoscopy remained limited due to the complexity of the surgical anatomy of the ampulla and the reconstruction required. However, the recent advancements of minimally invasive surgery (MIS) and growing expertise, in particular robotic assisted surgery, meant that some of these challenges could be mitigated. ${ }^{6}$ The first case of robotic TDA was reported in $2015 .^{7}$ We present a case of a robotic TDA performed for ampullary adenoma with high grade dysplasia and review the existing literature.

\section{CASE}

The patient was a 63-year-old male who initially pre-

Received: June 9, 2020; Revised: July 16, 2020; Accepted: July 24, 2020

Corresponding author: Brian K. P. Goh

Department of Hepatopancreatobiliary and Transplant Surgery, Singapore General Hospital, 20 College Road, Academia Level 5, Singapore 169856 Tel: +65-6326-5564, E-mail: bsgkp@hotmail.com

Copyright (C) 2021 by The Korean Association of Hepato-Biliary-Pancreatic Surgery

This is an Open Access article distributed under the terms of the Creative Commons Attribution Non-Commercial License (http://creativecommons.org/ censes/by-nc/4.0) which permits unrestricted non-commercial use, distribution, and reproduction in any medium, provided the original work is properly cited. Annals of Hepato-Biliary-Pancreatic Surgery - pISSN: 2508-5778 - elSSN: 2508-5859 
sented at another institution with deranged liver function tests. Magnetic resonance cholangiopancreatography performed showed dilated common bile duct with cutoff at an obstructing ampullary mass (Fig. 1). Endoscopic retrograde cholangiopancreatography (ERCP) and trawling was attempted but the lesion was immobile. Sphincterotomy was performed and biopsy of the lesion demonstrated focal high-grade dysplasia (HGD). As the patient was not keen for surgery, a follow up Spyglass choledochoscopy was performed which demonstrated an adenomatous tissue confined to the papilla with $5 \mathrm{~mm}$ extension into the common bile duct. Due to the bile duct extension, endoscopic resection was deemed to be at increased risk of harbouring a positive margin. Biopsies yielded adenomatous lesion with predominantly low-grade dysplasia (LGD) and focal HGD. Treatment options were discussed with the patient, including upfront PD versus TDA with possible PD if final histology turns out to be malignant. The patient ultimately opted for a robotic TDA.

Pre-operatively, ERCP and biliary stent insertion was performed to assist in easy identification of the ampulla via laparoscopic ultrasonography so has to limit the length of the duodenotomy. The patient was positioned supine. $12 \mathrm{~mm}$ port was inserted infra-umbilical for laparoscopic camera and another $12 \mathrm{~mm}$ port in the right iliac fossa. Further three $8 \mathrm{~mm}$ working ports were inserted in the left hypochondria, left flank and right hypochondria (Fig. 2). Diagnostic laparoscopy revealed multiple lesions in the

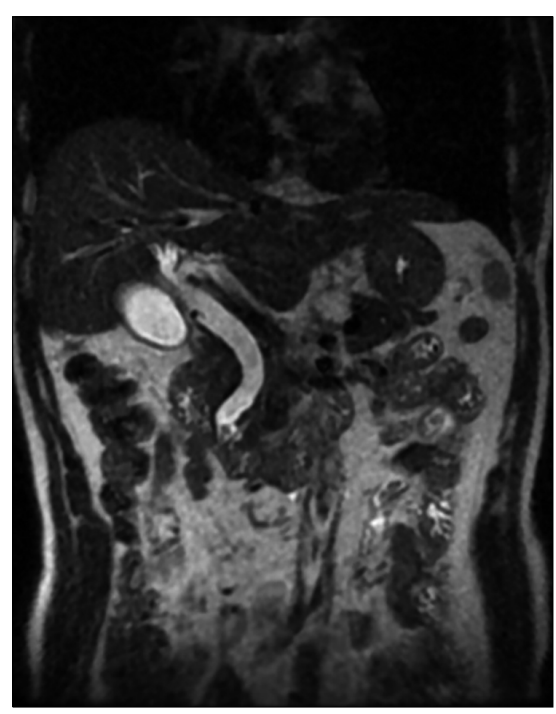

Fig. 1. MRCP showing dilated bile duct with cutoff at the obstructing ampullary mass. left lobe of the liver. Laparoscopic wedge resection of 2 liver lesions were performed and sent for frozen section. This demonstrated necrotising granulomatous inflammation suspicious for tuberculosis and decision was made to proceed with the robotic TDA.

Intraoperative laparoscopic ultrasound was than performed, which demonstrated the biliary stent at the ampulla. The main pancreatic duct was $3 \mathrm{~mm}$ in diameter. The hepatic flexure was than mobilised, greater omentum divided and duodenum was extensively kocherised to expose the entire D2. A longitudinal duodenotomy was then performed over the ampulla and the stent was noted to be in situ (Fig. 3). The duodenal walls were retracted with stay sutures. The ampulla was retracted and it was resected using mo-

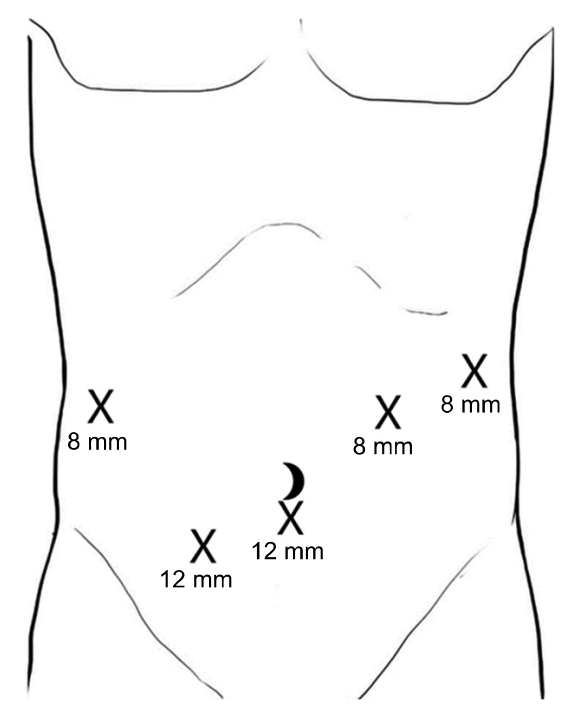

Fig. 2. Positioning of robotic ports.

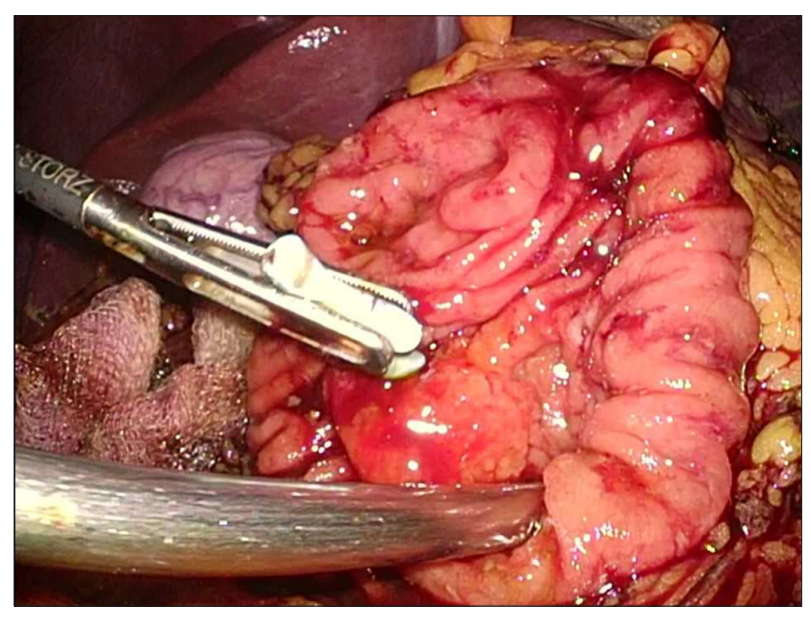

Fig. 3. Longitudinal duodenotomy over ampulla. 
nopolar diathermy hook until grossly clear resection margins. Frozen section was performed of the ampullary lesion yielding LGD and the resection margin was determined to be clear. The robot (Da Vinci Si, Intuitive Surgical, USA) was docked from the patient's head. The common bile duct and main pancreatic duct (Fig. 4) were identified and reconstructed with PDS 5/0 interrupted sutures (Figs. 5 and 6). The duodenotomy was closed with vicryl 3/0 (Fig. 7) and covered with omentum, Blake drains were left at the surgical site. The total operation time was 425 minutes. The estimated blood loss was $50 \mathrm{mls}$. Final histology of the ampullary tumour yielded LGD with negative margins, and histology of the liver nodule yielded necrotising granulomatous inflammation.

Post operatively, our patient's recovery was complicated by delayed gastric emptying (DGE) with persistently high nasogastric output, requiring a course of total parenteral nutrition (TPN). CT performed on the seventh post-operative day did not show any anastomotic leak or collections. His drains were removed on day five and six post oper-

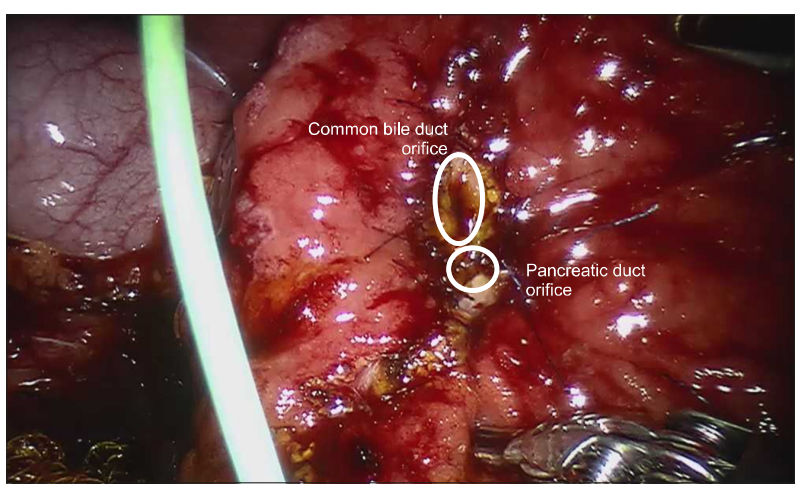

Fig. 4. Identification of common bile duct and main pancreatic duct.

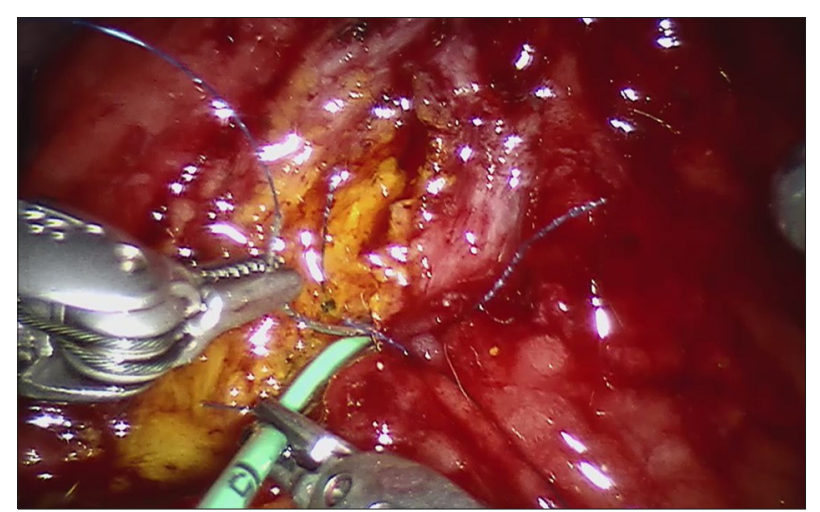

Fig. 5. Suturing of pancreatic duct orifice with aid of internal stent. atively and he was started on feeds day 14 post operation and diet day 20 post operation after contrast study on day 19 post operation demonstrated good flow of contrast with no stricture or leak. He was also reviewed by the infectious disease specialists, who started antimycobacterial agents for presumptive hepatic tuberculosis. He was discharged on the 27th post-operative day but was subsequently readmitted for fever from parainfluenza infection. He has since been well on last follow up 6 months postoperatively.

\section{DISCUSSION}

TDA was the first surgery described for malignancy involving the ampulla of Vater. It was first introduced in 1899 by Halsted, ${ }^{4}$ and performed via laparotomy. However, there were numerous problems initially associated with the procedure, including the lack of standardised indication and operative technique, as well as high recurrence rate. ${ }^{8}$ PD was then introduced by Whipple et al. ${ }^{9}$ in 1935, which became the gold standard for ampullary cancer. This was

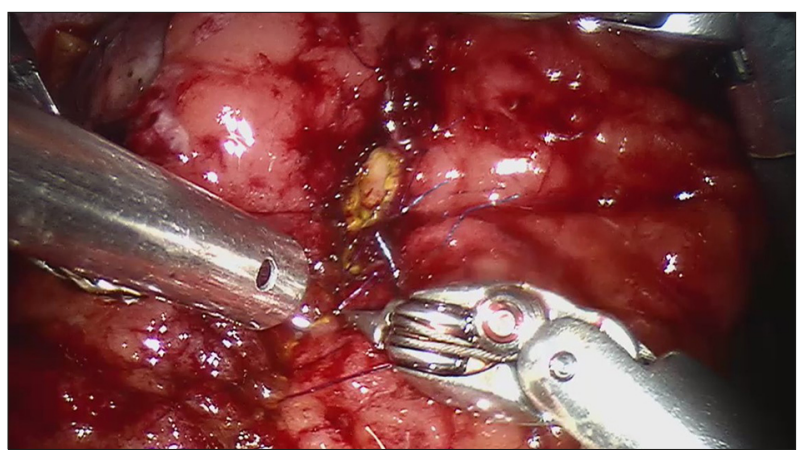

Fig. 6. Post reconstruction of main pancreatic duct and common bile duct.

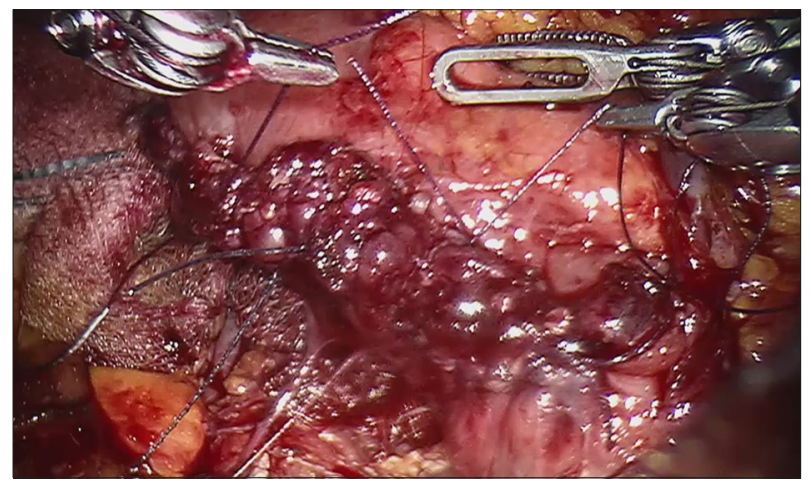

Fig. 7. Closure of duodenotomy with vicryl. 
however associated with significant perioperative morbidity, including post-operative pancreatic fistula, DGE and ductal stenosis. With developments in endoscopic technology, EP became an attractive minimally invasive option for benign tumours limited to the papilla with no ductal involvement as well as malignant tumours in patients with significant medical comorbidities that would preclude them for a PD. Despite its advantages of low morbidity and mortality rates, the use of EP is associated with an increased risk of an incomplete resection.

Today, with the increase utility of MIS and robotic surgery for hepatopancreaticobiliary conditions, ${ }^{10}$ complicated surgeries with the need for complex reconstruction can now be performed safely via MIS techniques with low rates of conversion to open surgery. ${ }^{11-14}$ In line with this trend, TDA was first reported to be performed laparoscopically in 2003. ${ }^{5}$ However, uptake of laparoscopic TDA has been limited due to several factors, including the technically demanding ductal reconstruction required as well as anatomical considerations such as working space. Much of these limitations can mitigated by the use of the robotic surgical platform. This offers a more ergonomic setup for the surgeon as well as increased dexterity ${ }^{8}$ over conventional laparoscopy which allows the surgeon to perform fine precise suturing in a narrow space.

A search of the current literature revealed 2 previous studies reporting on a total of 6 cases of robotic TDA (Table 1). Wong et al. ${ }^{6}$ presented the first published case of robotic TDA in Asia performed in Hong Kong in 2016, and Lee et al. ${ }^{15}$ presented a series of five cases in Korea in 2018. The overall mean age of patients who underwent robotic TDA was 56 (range, 26-78) years. There was 1 female and six males (Table 1). One patient presented with cholangitis and six were asymptomatic. All seven patients underwent pre-operative oesophageogastroduodenoscopy and biopsy of lesion; one had LGD and six had HGD. Three patients underwent pre-operative biliary stent placement via ERCP. The mean size of tumour is 1.96 (range 1.5 to 3$) \mathrm{cm}$. Intraoperative frozen section was sent for six of the seven patients. Median operative time was 210 minutes (180 to 350 minutes) and median blood loss was $50 \mathrm{ml}(20$ to $350 \mathrm{ml})$. Final histology was reported to be HGD in six patients and LGD in one patient, which all corresponded to their initial histologies. All margins were free of neoplasia. Median length of stay was 7 days (5 to 27 days). Two patients developed complications, including the patient reported by Lee et al., ${ }^{15}$ who developed bile duct stricture which failed ERCP cannulation requiring percutaneous drainage, and our patient who had DGE. No recurrence was reported. This compares favourably to the outcomes for open or laparoscopic TDA, ${ }^{3,16}$ although caution is needed in interpreting these small numbers.

The favourable outcomes with robotic TDA is likely attributable to the superior ergonomics and dexterity conferred by the robotic systems to the primary surgeon. ${ }^{17}$ This should be performed in specialised centres by surgeons with expertise in robotic surgery and in hepatopancreaticobiliary surgery. In our cases the primary surgeon had extensive prior experience in advanced minimally invasive hepatobiliary surgery, having performed over 400 minimally invasive major hepatopancreatobiliary procedures.

We find preoperative stenting to be useful in assisting with identifying the ampulla of Vater during surgery via use of ultrasound. This enables a more targeted duodenotomy, hence avoiding an unnecessarily long duodenotomy. Appropriate exposure is also key for this procedure's suc-

Table 1. Cases of robotic TDA performed in the literature

\begin{tabular}{|c|c|c|c|c|c|c|c|c|c|}
\hline Case & Author & $\begin{array}{l}\text { Age/ } \\
\text { gender }\end{array}$ & $\begin{array}{l}\text { Size } \\
(\mathrm{cm})\end{array}$ & Pathology & $\begin{array}{l}\text { Operative } \\
\text { time (min) }\end{array}$ & $\begin{array}{l}\text { Blood loss } \\
\quad(\mathrm{mls})\end{array}$ & Morbidity & $\begin{array}{l}\text { Length of } \\
\text { stay }\end{array}$ & Margin \\
\hline 1 & Current study & $63 \mathrm{M}$ & 2.0 & HGD & 305 & 50 & $\begin{array}{l}\text { DGE, } \\
\text { abdominal } \\
\text { collection }\end{array}$ & 27 & Free \\
\hline 2 & Wong et al. ${ }^{6}$ & $63 \mathrm{~F}$ & - & HGD & 250 & 20 & Nil & 7 & - \\
\hline 3 & Lee et al. ${ }^{15}$ & $78 \mathrm{M}$ & 3.0 & HGD & 350 & 350 & $\begin{array}{l}\text { Biliary } \\
\text { stricture }\end{array}$ & 8 & Free \\
\hline 4 & Lee et al. ${ }^{15}$ & $42 \mathrm{M}$ & 1.5 & HGD & 210 & 150 & Nil & 6 & Free \\
\hline 5 & Lee et al. ${ }^{15}$ & $26 \mathrm{M}$ & 2.0 & HGD & 190 & 170 & Nil & 5 & Free \\
\hline 6 & Lee et al. ${ }^{15}$ & $76 \mathrm{M}$ & 1.5 & HGD & 200 & 30 & Nil & 7 & Free \\
\hline
\end{tabular}


cess. Extensive kocherisation was needed to expose D2 for ourcase, and the duodenal wall was retracted with the use of stay sutures. Appropriate discussion with patients on the limitations of TDA is also important, and they should be made aware of the need to proceed with PD if intraoperative frozen section found extension beyond the biliary ducts or to the muscle layer of the duodenal wall.

We conclude that robotic TDA is a safe and effective alternative to traditional open and laparoscopic approach for the resection of ampullary neoplasms. As the uptake of MIS among hepatopancreaticobiliary surgeons increase, we expect more robotic TDA to be performed in future. Further studies would benefit from the increasing numbers in establishing the role of robotic TDA compared to traditional open surgery and laparoscopic surgery.

\section{CONFLICT OF INTEREST}

The authors have no potential conflicts of interest to disclose.

\section{ORCID}

Yun Le Linn: https://orcid.org/0000-0002-7119-4178

Zhongkai Wang: https://orcid.org/0000-0002-7090-3972

Brian K. P. Goh: https://orcid.org/0000-0001-8218-4576

\section{AUTHOR CONTRIBUTIONS}

Conceptualization: YLL, BKPG. Data curation: YLL, ZW. Formal analysis: YLL, ZW, BKPG. Methodology: YLL, ZW. Project administration: BKPG. Visualization: YLL. Writing - original draft: YLL, ZW. Writing - review \& editing: BKPG.

\section{REFERENCES}

1. Albores-Saavedra J, Schwartz AM, Batich K, Henson DE. Cancers of the ampulla of vater: demographics, morphology, and survival based on 5,625 cases from the SEER program. J Surg Oncol 2009;
100:598-605.

2. Stolte M, Pscherer C. Adenoma-carcinoma sequence in the papilla of Vater. Scand J Gastroenterol 1996;31:376-382.

3. Nappo G, Gentile D, Galvanin J, Capretti G, Ridolfi C, Petitti $\mathrm{T}$, et al. Trans-duodenal ampullectomy for ampullary neoplasms: early and long-term outcomes in 36 consecutive patients. Surg Endosc 2020;34:4358-4368.

4. Halsted WS. Contributions to the surgery of the bile passages, especially of the common bile-duct. Boston Med Surg J 1899;141:645-654.

5. Rosen M, Zuccaro G, Brody F. Laparoscopic resection of a periampullary villous adenoma. Surg Endosc 2003;17:1322-1323.

6. Wong FCH, Lai ECH, Chung DTM, Tang CN. Robotic transduodenal excision of ampullary tumour. Hepatobiliary Surg Nutr 2017; 6:312-316.

7. Downs-Canner S, Van der Vliet WJ, Thoolen SJ, Boone BA, Zureikat AH, Hogg ME, et al. Robotic surgery for benign duodenal tumors. J Gastrointest Surg 2015;19:306-312.

8. Kim J, Choi SH, Choi DW, Heo JS, Jang KT. Role of transduodenal ampullectomy for tumors of the ampulla of Vater. J Korean Surg Soc 2011;81:250-256.

9. Whipple AO, Parsons WB, Mullins CR. Treatment of carcinoma of the ampulla of Vater. Ann Surg 1935;102:763-779.

10. Goh BKP, Low TY, Lee SY, Chan CY, Chung AYF, Ooi LLPJ. Initial experience with robotic pancreatic surgery in Singapore: single institution experience with 30 consecutive cases. ANZ J Surg 2019;89:206-210.

11. Goh BKP, Low TY, Kam JH, Lee SY, Chan CY. Initial experience with laparoscopic and robotic surgery for the treatment of periampullary tumours: single institution experience with the first 30 consecutive cases. ANZ J Surg 2019;89:E137-E141.

12. Low TY, Goh BKP. Initial experience with minimally invasive extended pancreatectomies for locally advanced pancreatic malignancies: report of six cases. J Minim Access Surg 2019;15:204209.

13. Goh BKP, Zeng G, Low TY, Chua DW, Koh YX, Lim KI. Changing trends and outcomes associated with the adoption of minimally-invasive pancreato-biliary surgery: contemporary experience of a 'self-taught' early adopter in Southeast Asia. J Minim Access Surg 2020;16:341-347.

14. Goh BK, Low TY, Koh YX, Lee SY, Teo JY, Kam JH, et al. Changing trends and outcomes associated with the adoption of minimally invasive pancreatic surgeries: a single institution experience with 150 consecutive procedures in Southeast Asia. J Minim Access Surg 2020;16:404-410.

15. Lee JW, Choi SH, Chon HJ, Kim DJ, Kim G, Kwon CI, et al. Robotic transduodenal ampullectomy: a novel minimally invasive approach for ampullary neoplasms. Int J Med Robot 2019; 15:e1979.

16. Hong S, Song KB, Lee YJ, Park KM, Kim SC, Hwang DW, et al. Transduodenal ampullectomy for ampullary tumors - single center experience of consecutive 26 patients. Ann Surg Treat Res 2018;95:22-28.

17. Goh BK, Teo RY. Current status of laparoscopic and robotic pancreatic surgery and its adoption in Singapore. Ann Acad Med Singap 2020;49:377-383. 